\title{
CONTRATOS ELETRÔNICOS E A PROTEÇÃO DE DADOS PESSOAIS DO CONSUMIDOR: DIÁLOGO DE FONTES ENTRE O CÓDIGO DE DEFESA DO CONSUMIDOR E O MARCO CIVIL DA INTERNET.
}

\section{ELECTRONIC CONTRACTS AND THE PERSONAL DATA PROTECTION OF THE CONSUMER: SOURCES DIALOGUE BETWEEN THE CONSUMER PROTECTION CODE AND THE INTERNET CIVIL MARK.}

\author{
${ }^{1}$ Rosane Leal Da Silva
}

\section{RESUMO}

Este artigo analisa a proteção de dados pessoais do consumidor e sua vulnerabilidade nos contratos eletrônicos interativos, objetivando apontar meios de defesa. Para tanto utiliza a abordagem dedutiva e parte da contratação eletrônica para discutir a proteção jurídica do consumidor em face da captura e tratamento de seus dados pessoais pelo fornecedor. Considerando inexistência de lei sobre dados pessoais, conclui-se que a contratação eletrônica amplia a vulnerabilidade do consumidor, o que exige a aplicação dos princípios do Código de Defesa do Consumidor, agregando-se o Marco Civil da Internet no que se refere à proteção da privacidade.

Palavras-chave: Comércio eletrônico, Dados pessoais, Proteção do consumidor

\begin{abstract}
This paper analyzes the personal data protection of the consumer and your vulnerability in interactive electronic contracts, aiming to point means of defense. For this, uses the deductive approach and starts of the electronic contracting to discuss the legal protection of the consumer in light of the capturing and processing of personal data by the furnisher. Considering the absence of law about personal data, concludes that electronic contracting expands the consumer vulnerability, which requires the principles application of the Consumer Protection Code, adding the Internet Civil Mark in relation to the privacy protection.
\end{abstract}

Keywords: E-commerce, Personal data, Consumer protection

\footnotetext{
${ }^{1}$ Doutora em Direito pela Universidade Federal de Santa Catarina - UFSC, Florianópolis, (Brasil). Professora Adjunta da Universidade Federal de Santa Maria - UFSM, Rio Grande do Sul, Brasil. E-mail: rolealdasilva@gmail.com
} 


\section{INTRODUÇÃO}

O crescente acesso dos brasileiros à internet, seja por meio de computadores ou por dispositivos móveis, tem contribuído significativamente para movimentar a economia do imaterial. De posse de um dispositivo conectado à internet qualquer usuário pode acessar e facilmente realizar contratos eletrônicos, o que poderá ocorrer independente das fronteiras geográfica.

Se por um lado a facilidade em adquirir bens e serviços mantém a economia aquecida, revelando-se vital para a manutenção de muitas empresas, especialmente em épocas de crise econômica, e permite melhores opções de negócios com menor custo ao consumidor, por outro lado essa economia calcada no comércio eletrônico origina crescentes vulnerabilidades para os dados pessoais dos internautas, tema que será objeto dessa análise.

Apesar da importância dos dados pessoais e da autonomia conferida em muitos diplomas legais estrangeiros, o Brasil não conta com um sistema específico organizado para a tutela desse direito dos internautas. A recente edição da Lei no 12.965/2014 (Marco Civil da Internet) trouxe alguma proteção, mas ficou aquém do necessário, sobretudo considerando a dinâmica da contratação online. A esse cenário se soma a tendência de muitos juristas em atuarem dentro de seus campos delimitados de saber, buscando as respostas apenas na regulação setorial, quando a visão na perspectiva de sistema jurídico poderia dar respostas mais adequadas para os novos conflitos que se desencadeiam nessa quadra da história. Este é, portanto, o objetivo do presente trabalho, que visa a apresentar algumas das vulnerabilidades que os contratos eletrônicos interativos apresentam aos internautas, propondo discutir o tema a partir de uma perspectiva integrada.

Assim, tendo em vista que muitas dessas práticas violadoras ocorrem em contratos interativos de consumo, onde é maior a vulnerabilidade do titular dos dados, entende-se que o tema também será regrado pelo Código de Defesa do Consumidor. No entanto, numa primeira leitura nenhuma dessas legislações, de maneira isolada, parece responder satisfatoriamente em tutelar os dados pessoais do internauta, sobretudo aquele que realiza contratos interativos na internet.

Essa insuficiência remete ao seguinte questionamento: a aplicação combinada e complementar dessas duas legislações especiais poderia se constituir em alternativa para ampliar a proteção dos dados pessoais? Qual o elemento comum entre os dois diplomas legais que facilitaria essa convergência e o diálogo das fontes? 
Para responder a esses questionamentos partiu-se de uma visão mais ampla do fenômeno da contratação eletrônica na sociedade em rede, utilizando abordagem dedutiva para, em perspectiva descendente, analisar as práticas realizadas pelas empresas, especialmente diante dos contratos eletrônicos interativos, discutindo a melhor maneira de proteger os dados pessoais do internauta contratante.

\section{O COMÉRCIO ELETRÔNICO NA SOCIEDADE EM REDE.}

Cada período histórico é marcado pela existência e utilização de tecnologias que não somente geram novas experiências que caracterizam o modo de ser e estar no mundo, como imprimem um ritmo próprio a este tempo, distinguindo-o dos demais períodos históricos.

O atual cenário é conformado pela crescente utilização das Tecnologias da Informação e da Comunicação (TICs), tendo a internet como um dos principais motores dessa transformação, responsável, em grande parte, por realizar a transposição da sociedade industrial para a informacional. Essa expressão é utilizada por Castells para explicitar a abrangência e a profundidade das transformações, que já não se ancoram somente na informação considerada em seu aspecto estático, mas tomam como ponto de partida os complexos informacionais que estão em constante transformação, com potencial para gerar conhecimento e reconfigurar a própria sociedade.

Esta nova morfologia, diversamente das anteriores formas de organização social, não reproduz o modus operandi "do vigilantismo, do esquadrinhamento do espaço, do monitoramento das ações dos indivíduos, características da sociedade disciplinar analisada por Michel Foucault, utilizavam as informações dos indivíduos de forma diferente dos usos atuais" (SEGURADO; LIMA; AMENI, 2015, p.1555). Se antes as informações estavam organizadas atendendo a uma estrutura compartimentalizada, com forte tendência vertical e hierárquica, onde seu acesso dependia da posição do indivíduo na estrutura de poder, a conformação atual mostra-se mais flexível e dinâmica, utilizando-se das tecnologias para sofisticar os sistemas de recolhimento, tratamento e transmissão de informações. Os conceitos de tempo e espaço se relativizam, fazendo com que Estados, empresas e indivíduos já não operem a partir de locais fixos e balizados pelas fronteiras territoriais dos Estados. Ao revés, abandona os esquemas lineares e unidimensionais em favor de uma conformação menos precisa, mais aberta e interativa, na qual os atores sociais podem criar e assumir diversos papéis. 
O acesso à informação e as possibilidades de comunicação ganham instantaneidade e fenômenos locais, antes isolados no âmbito territorial do Estado, agora rapidamente se propagam além fronteiras. Tudo é local e global ao mesmo tempo, numa interpenetração que não é somente espacial, já que também o tempo é comprimido pela instantaneidade dos fluxos, formando novas redes. Essa dinâmica origina um novo conceito de sociedade. Como explicado por Castells (2013, p.58),

\begin{abstract}
Uma sociedade em rede é aquela cuja estrutura social é composta de redes activadas por tecnologias digitais de comunicação e informação baseadas em microelecrónica. Entendo por estrutura social os acordos organizativos humanos na relação com a produção, o consumo, a reprodução, a experiência e o poder expressos por uma comunicação significativa codificada pela cultura.
\end{abstract}

Na sociedade em rede a informação, sua produção, publicação e compartilhamento assumem papel muito importante e conferem poder, o que tanto atinge as tradicionais instituições, como o Estado, quanto também empodera os cidadãos (individual e coletivamente) e as empresas. Essas, por sua vez, têm na informação e nos dados de seus clientes um poderoso insumo, o que pode tanto ampliar e melhorar os negócios, como valorizar a própria empresa, que pode inclusive negociar seu banco de dados.

As transformações, a par de profundas, também são amplas, atingindo vários domínios, como o político, o social e o econômico, o que leva Castells (1999, p.46) a afirmar que se vive numa nova morfologia social, e esta nova organização em rede expande-se e revela novas oportunidades e inéditos problemas.

Nessa nova configuração ocorre a interpenetração de meios de produção, dando destaque à economia do imaterial, onde a antiga produção de bens corpóreos passa a conviver com uma nova dinâmica econômica ditada pelo comércio eletrônico. Segundo as contribuições de Feitosa e Garcia (2016, p.87),

\footnotetext{
O comércio eletrônico é definido como qualquer transação econômica em que compradores e vendedores se comunicam por meio de mídias eletrônicas da Internet, firmam um acordo contratual no que diz respeito ao estabelecimento de preços e entrega de bens/serviços específicos, e consolidam a transação por meio da execução do pagamento e da entrega desses bens/serviços, conforme estabelecido em contrato (Guay \& Ettwein, 1998; Turban \& King, 2004).
}

Esse comércio pauta-se nos contratos, negócios jurídicos em crescente expansão na sociedade em rede. Claudia Lima Marques (2004, p.35-36) ao tratar do tema, além de destacar o papel que as tecnologias desempenham ao dispensar a presença física dos contratantes, ainda evidencia a transformação rumo a uma economia intangível, pois esses negócios 
envolvem tanto operações tradicionais de compra e venda, como a prestação de serviços e as de dados digitais, textos, sons e imagens.

Martins (2000, p.139) explica que os contratos eletrônicos podem se apresentar sob duas modalidades principais, envolvendo a prestação para ser consumida “[...] diretamente pelo meio da multimídia (como é o caso dos serviços de informações, dos bancos de dados e dos serviços de mensagens eletrônicas) e a compra e venda de bens ou a prestação de serviços a serem executados ou entregues por um outro meio [...]".

Segundo classificação desenvolvida por Barbagalo (2001, p.51), os contratos eletrônicos podem se apresentar como contratos intersistêmicos ${ }^{1}$, contratos interpessoais ${ }^{2}$ e contratos interativos, espécie que oferece maior interesse para fins deste estudo. Nesta última modalidade de contratação o internauta interage com um sistema já preparado, no qual os produtos e serviços são ofertados num site destinado ao processamento eletrônico de informações e, como ensinado por Barbagalo (2001, p.57), essa forma pode ser considerada como "contratos de adesão", pois o instrumento já conterá todos os dados necessários à contratação, bastando a anuência do consumidor às regras já estabelecidas ou às "condições gerais dos contratos" expostas no site. Portanto, nessa forma de contratação o internauta ingressa no site organizado pela empresa (que tanto pode ter estabelecimento físico ou somente realizar contratações virtuais), interage com os produtos e serviços disponíveis (usualmente descritos no site e com recursos para a visualização de suas especificidades) e, em caso de interesse na efetivação do contrato, elege a forma de pagamento e disponibiliza os dados pessoais e bancários para a consumação da operação.

Ainda que não se possa sustentar que a contratação eletrônica constitui nova espécie de contrato é inegável que o uso de TIC permite novas aplicações e revela algumas especificidades, tanto na fase de sua formação, quanto na sua execução. Como advertem Marques e Martins (2006, p.403), há maior vulnerabilidade do consumidor ${ }^{3}$, o que vai desde

\footnotetext{
${ }^{1}$ Nesta forma de contratação as necessidades contratuais já foram explicitadas pelas partes e as vontades já se harmonizaram, sendo a TIC apenas um instrumento para a transmissão do que anteriormente foi acordado, sem que o equipamento interligado em rede tenha interferência na formação das vontades dos contratantes (BARBAGALO, 2001, p.51).

${ }^{2}$ Os contratos interpessoais são aqueles em que as partes utilizam o computador como meio de comunicação entre si, interagindo na formação da vontade destes e na instrumentalização do contrato, não sendo apenas forma de comunicação de vontade já concebida. Como ensinado por Barbagalo (2001, p.53), nesta forma de contratação há interação humana nos dois extremos e isso pode ocorrer simultaneamente, como nas contratações via chat ou por e-mail, caracterizando a contratação entre ausentes neste segundo caso (BARBAGALO, 2001, p.55).

${ }_{3}^{3}$ Conforme Marques, Benjamin e Miragem (2010, p.197), a vulnerabilidade é um estado da pessoa, um estado inerente de risco ou um sinal de confrontação excessiva de interesse, cuja aplicação não pode ocorrer se não à luz do caso concreto e do exame detido das suas vicissitudes. E tanto é assim que de acordo com os arts. $2^{\circ}$ e $4^{\circ}$ I, do Código de Defesa do Consumidor, a vulnerabilidade é presumida para as pessoas físicas destinatárias finais
} 
eventual falta de informação sobre produto ou serviço, desconhecimento dos direitos do consumidor, quanto a maior fragilidade "[...] em face de técnicas de promoção e de venda nem sempre leais". A esses problemas podem ser agregados outros, como insegurança do destino conferido aos seus dados pessoais disponibilizados no momento de realização da contratação online. É sobre essa temática que será aprofundado o estudo, conforme se verá na próxima parte do artigo.

\section{A PROTEÇÃO DOS DADOS DO CONSUMIDOR NA NOVA ECONOMIA VIRTUAL.}

A economia virtual tende a expandir-se, mesmo em períodos de crise. Dados relativos ao uso da internet para comércio eletrônico mostram que no Brasil o faturamento neste segmento apresentou, nos últimos anos, acentuado ritmo de crescimento: em 2012 foi registrado um movimento de $\mathrm{R} \$ 22,5$ (vinte e dois vírgula cinco) bilhões, valores elevados para $\mathrm{R}$ \$ 28,8 (vinte e oito vírgula oito) bilhões em 2013. No ano de 2014, marcado por forte queda no crescimento econômico, o comércio eletrônico chegou a patamares de $\mathrm{R}$ \$ 35,8 (trinta e oito vírgula oito) bilhões, atingindo percentual de $24 \%$ (vinte e quatro por cento) de vendas pela internet (RELATÓRIO WEBSHOPPERS, 2015, p.8).

A crise financeira gerada nos últimos dois anos, somado às instabilidades políticas e institucionais trouxeram reflexos sobre todo o mercado, atingindo o consumo dos brasileiros e onerando, sobretudo, a emergente classe $\mathrm{C}$, que estava se inserindo na economia informacional e registrou retração. No entanto, ainda com esse encolhimento os dados do Relatório Webshoppers (2016, p.30) informam que

Apesar do ritmo menos acelerado, as vendas no comércio eletrônico em 2015, no Brasil, mantiveram a ascensão e, novamente, apresentaram crescimento. Segundo os dados coletados, o faturamento do comércio eletrônico foi de $\mathrm{R} \$ 41,3$ bilhões. O número representa um crescimento nominal de $15,3 \%$, em relação a 2014 , quando as vendas somaram um total de $\mathrm{R} \$ 35,8$ bilhões.

do serviço e do produto e se desdobra em três sub-espécies: a) a vulnerabilidade técnica, que se manifesta na falta de conhecimentos específicos sobre o produto ou serviço que está adquirindo, típica do consumidor não profissional, conforme ensinam Marques, Benjamin e Miragem (2010, p.198); b) a vulnerabilidade jurídica, que se caracteriza pela ausência de conhecimentos jurídicos, da área contábil ou econômica implicada na contratação, o que dificulta ao consumidor não profissional o entendimento dos termos do contrato e de suas consequências; c) vulnerabilidade fática, na qual há desproporção real de forças intelectuais e econômicas, desequilíbrio que tipicamente caracteriza a relação de consumo. 
A tendência é estes índices de transações não decaírem significativamente, pois ainda que o ano de 2016 registre um momento econômico e político bastante instável, as empresas, por outro lado, estão reduzindo custos, operando dentro de uma nova racionalidade que inclui reduzir parcelamentos e rever a política de frete grátis, medidas que se aliam ao constante monitoramento do comportamento dos consumidores, como se constata da manifestação de Cristiane Camargo (RELATÓRIO WEBSHOPPERS, 2016, p.20).

\footnotetext{
Monitorar o comportamento do consumidor é, sem dúvida, uma área fascinante para os profissionais de marketing. E isto torna-se muito mais interessante quando os dados capturados passam a ser insumo para o desenho de uma estratégia, e a tecnologia é apenas o palco para uma atuação brilhante das marcas, produtos e serviços.
}

As práticas de monitoramento tornam-se estratégias constantes para as empresas que operam no comércio virtual, especialmente para determinar o perfil do consumidor e enviar ofertas e serviços direcionados. O levantamento realizado permite afirmar, por exemplo, que “39,1 milhões de consumidores virtuais realizaram pelo menos uma compra em 2015, volume 3\% maior que em 2014”, (RELATÓRIO WEBSHOPPERS, 2016, p.16), havendo uma perfeita divisão de gênero, pois metade dos consumidores online pertencia ao sexo masculino e a outra metade era composta por pessoas do sexo feminino, tendo idade média de 43 anos, localizados predominantemente no Estado de São Paulo (registra 37,7 dos consumidores), sendo que o percentual mais expressivo (39\%) dos negociantes registrou renda inferior a $\mathrm{R} \$$ 3.000,00 (RELATÓRIO WEBSHOPPERS, 2016, p.24). Dentre os compradores, 73,5\% utiliza de cartão de crédito para realizar o pagamento (RELATÓRIO WEBSHOPPERS, 2016, p.27), o que significa dizer que informa dados pessoais ao realizar a contratação.

Além das informações coletadas na etapa de realização da compra online, é comum as empresas utilizarem tecnologias para seguir os movimentos do internauta, ocasião em que todos movimentos do potencial consumidor passam a ter interesse, pois

\footnotetext{
Quando se visita um site, as páginas, a quantidade de tempo que cada página é visualizada, os links clicados, as buscas feitas e as interações realizadas ficam armazenadas, possibilitando que sites coletem os dados para que se crie um „perfil" dos usuários (MASINA, 2014, p.21).
}

Ainda que sob o ponto de vista empresarial tal acompanhamento e recolhimento de informações possam se justificar por contribuir para melhorar o marketing e incrementar o comércio eletrônico, por outro lado se constitui em violação da privacidade do usuário, não só 
devassando suas práticas online, quanto também recolhendo e tratando seus dados pessoais, o que muitas vezes é feito sem o seu conhecimento e autorização.

A utilização de TICs evidencia que a tradicional Teoria de Hubmann, que utiliza o esquema de esferas concêntricas para evidenciar os diferentes graus de privacidade já não se sustenta. Segundo esta teoria a camada mais fechada e próxima do núcleo central da pessoa seria aquela reservada à esfera da intimidade ou do segredo, cujos assuntos só interessariam ao titular do direito. Essa camada mais fechada seria abrangida pela esfera privada, um pouco mais ampla e que permitiria que os dados e informações ali constantes chegassem ao conhecimento de um limitado grupo de pessoas eleitas pelo titular do direito, sendo esta esfera encoberta pela pessoal, que abrangeria informações e dados que seriam do conhecimento público (DONEDA, 2006, p.67). Em tempos atuais percebe-se sua insuficiência, pois não há como controlar e impor limites a quem, por meio do uso de tecnologia, adentra na esfera que deveria ser reservada ao segredo do internauta como, por exemplo, os sites que visita ou os produtos que busca, atividades que em princípio deveriam ficar protegidas pelo manto da reserva.

$\mathrm{O}$ atual modelo de monitoramento das empresas que atuam no comércio eletrônico evidencia a necessidade de pensar o tema a partir de uma visão unitária e que favoreça a autodeterminação informativa, ou seja, que empodere o consumidor para que ele tenha controle sobre seus dados pessoais. Tal como ensinado por Pérez Luño (2005, p.338-9), o tratamento da privacidade precisa ser ampliado, pois “[...] a intimidade, tal como se tem estudado, para além de uma possibilidade de isolamento implica um direito de participação e de controle das informações que concernem a cada pessoa".

Com acerto, Pérez Luño (2005, p. 336) enfatiza a insuficiência de "conceber a intimidade como um direito garantia (status negativo) de defesa frente a qualquer invasão indevida a esfera privada, sem contemplá-la, ao mesmo tempo, como um direito ativo de controle (status positivo) sobre o fluxo de informações que afetam cada sujeito". Essa nova visão impõe, também, que se estenda a proteção da intimidade aos dados pessoais.

Portanto, considerando as novas formas de obtenção e tratamento das informações existentes na sociedade em rede, Catarina Sarmento e Castro (2005, p.74) definiu os dados pessoais como toda aquela informação que permite “[...] identificar uma pessoa - desde logo se surgem associados a um nome -, as suas classificações escolares, curriculum, a sua história clínica, as suas dívidas e créditos, as compras que efetua, o registro dos meios de pagamento que utiliza”. Em sentido similar encontram-se as lições de Maria Eduarda Gonçalves (2003, p.89) para quem dado pessoal é "qualquer informação relativa a uma pessoa física 
identificada ou identificável (artigo $2^{\circ}$ ). Uma pessoa física não é considerada identificável se a sua identificação requer tempo, custos ou atividades exageradas."

Com ensina Gonçalves (2003, p.90), os dados receberão tratamento diferenciado a depender do seu conteúdo e do risco que a sua eventual divulgação possa trazer para o titular, pois “[...] dados de caráter pessoal que revelem origem racial, as opiniões políticas, as convicções religiosas ou outras convicções, assim como os dados pessoais relativos à saúde ou a vida sexual, não podem ser tratados automaticamente[...]", o que evidencia que nesses casos a proteção conferida pelo ordenamento jurídico deve ser maior.

Esta proteção realmente precisa ser alargada em face das apuradas técnicas que Estados e empresas dispõem para ampliar e aprofundar a vigilância sobre os cidadãos, o que ocorre independentemente do seu conhecimento e autorização. Quanto à atuação do mercado, Klee e Martins (2015, p.293) afirmam que

\begin{abstract}
A ameaça de violação dos direitos de personalidade vem das empresas que coletam, armazenam, processam e transmitem dados de seus clientes e consumidores para outras empresas e órgãos estatais. A tecnologia da informação permite transformar dados parciais e dispersos em informação em massa e organizadas. [...]

A violação do direito de privacidade na sociedade da informação passa a significar, por exemplo, o risco do uso indevido de dados pessoais, da classificação de indivíduos por características comuns, como o perfil de consumo, de imposição de comportamentos padronizados e de discriminação dos cidadãos.
\end{abstract}

Considerando o aporte tecnológico existente e a admissão de que as empresas realizam o monitoramento (RELATÓRIO WEBSHOPPERS, 2016, p.20) dos internautas, é plausível pensar que dados referentes à saúde do internauta, como busca por informações sobre doenças ou medicamentos e até mesmo dados relacionados com sua opção sexual, todos geradores de discriminação, podem facilmente chegar ao conhecimento de quem atua no segmento de comércio eletrônico. Tal vulnerabilidade ratifica a necessidade da autodeterminação informacional.

Tal conceito, que não é novo e já vinha sendo empregado pela doutrina estrangeira e brasileira não encontrava, todavia, amparo na legislação brasileira. Esta situação se alterou com o advento da Lei n ${ }^{\circ} 12.965 / 2014^{4}$, denominada Marco Civil da Internet, que se ancora no

\footnotetext{
${ }^{4}$ O Marco Civil da Internet se notabilizou por seu inédito processo de elaboração, tendo se iniciado em 2009 por meio de uma parceria entre a Secretaria de Assuntos Legislativos do Ministério da Justiça (SAL/MJ) e a Escola de Direito do Rio de Janeiro da Fundação Getúlio Vargas (DIREITO RIO), com a atuação específica do Centro de Tecnologia e Sociedade (CTS/FGV) (COMITÊ GESTOR DA INTERNET, 2013). Para tanto foi desenvolvida uma plataforma na internet hospedada no site CulturaDigital.br, onde inicialmente foi divulgado um texto-base produzido pelo Ministério da Justiça, no qual identificava e propunha a sistematização dos principais temas referentes à internet que se encontram pendentes de regulação no país. Partindo dessa publicação, membros do governo, sociedade civil, representantes dos provedores e do terceiro setor,
} 
princípio da autodeterminação informacional. Destaque-se, quanto a este tema, a contribuição de Lima e Bioni (205, p.267) segundo a qual a autodetermnação informacional é

[...] fundada na perspectiva de que o próprio usuário deve ter controle sobre as suas informações pessoais, autodeterminando-as. Socorre-se, por isso, da técnica de exigir o consentimento do titular dos dados pessoais para que eles sejam coletados, processuais e compartilhados, seguindo-os em todos os seus movimentos.

Com efeito, não se discute a relevância desse princípio, expresso no artigo $7^{\circ}$ do Marco Civil da Internet, tampouco se questiona a necessidade de o consumidor consentir com a captura e tratamento de seus dados, aquiescência que deve ser renovada. A questão que parece mais delicada refere-se às situações em que os dados são coletados sem o conhecimento do internauta por meio de sofisticadas técnicas de monitoramento e coleta utilizadas pelas empresas, dentre elas o emprego de cookies ${ }^{5}$. Portanto, se uma alternativa consiste no fortalecimento da autonomia do titular dos dados, que teria que consentir (como expresso na Lei $\mathrm{n}^{\mathrm{o}}$ 12.965/2014) outra opção diametralmente oposta seria partir do reconhecimento do desequilíbrio da relação entre consumidor e fornecedor, o que macularia esse consentimento. Segundo Doneda (2015, p.373), “[...] determinadas modalidades de tratamento de dados pessoais necessitam de uma proteção no seu mais alto grau, que não pode ser conferida exclusivamente a uma decisão individual pela dificuldade de que se tenha uma real noção dos efeitos decorrentes do tratamento de dados [...]". O autor sustenta que uma alternativa seria seguir o caminho trilhado por muitas legislações, a exemplo dos Estados que internalizaram em suas legislações os princípios pregados pelas Diretivas da União Europeia (em especial o teor da Diretiva 95/46/CE), adotando uma autoridade independente para tutelar os dados pessoais dos usuários. Também defende a edição das chamadas normativas conexas, que seriam normas para o tratamento da informação em determinado segmento, como saúde ou crédito ao consumo.

Essas não são as únicas alternativas (e tampouco elas podem ser vistas como excludentes), pois outras formas de minorar essa vulnerabilidade seria os próprios usuários

representantes da academia e todos os demais interessados no tema foram incentivados a participar dos debates e publicar suas contribuições, num processo de construção coletiva que posteriormente resultou na Lei 12.965/2014. (MARCO CIVIL DA INTERNET, 2014).

${ }^{5}$ Segundo definição de Borgesius (2014, p.10) cookie “[...] é um pequeno arquivo de texto que um editor de sítios na Internet armazena no computador ou no smartphone de um usuário para reconhecer aquele dispositivo. [...] Normalmente, esses cookies são relativos à "sessão", pois desaparecem depois que o usuário fecha o navegador. As empresas que atuam na segmentação comportamental costumam usar cookies persistentes para reconhecer os usuários em momentos futuros. Aquelas que publicam anúncios num sítio, como as redes de propaganda, podem colocar e ler também esses cookies persistentes [...] Resulta daí que uma rede de propaganda pode acompanhar o comportamento de um usuário da Internet em todos os sítios nos quais ela publica anúncios". 
adotarem modos de navegação privados, bem como os navegadores criarem obstáculos para a instalação de cookies sem o consentimento expresso do internauta, ambas estratégias referidas por Lima e Bioni (2015, p.282):

\begin{abstract}
Por isso, a configuração do padrão de um brouser para frear a coleta dos dados pessoais dos usuários, admitindo-se, somente, que tal prática ocorra com o seu consentimento expresso e informado a ser obtido durante a navegação mediante uma interação com tal aplicação, é o caminho mais factível para que o modelo normativo desenhado pelo MCI desempenhe uma efetiva proteção dos dados pessoais.
\end{abstract}

As medidas apontadas pela doutrina brasileira que comenta o tema após o advento do Marco Civil da Internet têm potencial para ampliar a proteção dos dados pessoais do consumidor. No entanto, sua efetivação não ocorrerá automaticamente, pois ou exigem legislação específica, como ocorre no caso da atuação da autoridade administrativa independente, ou dependem da disponibilização de mecanismos por parte do navegador. Portanto, ainda que a recente legislação tenha contemplado a defesa da privacidade do internauta, erigida a um dos seus princípios, são necessárias outras medidas, o que demonstra ainda persistir a vulnerabilidade, especialmente considerando a sofisticação das estratégias adotadas pelo mercado e as assimetrias entre os atores da relação de consumo. Tal constatação remete para a necessidade de diálogo das fontes, aliando-se a recente proteção do Marco Civil da Internet com a proteção prevista no Código de Defesa do Consumidor, conforme se sustentará na sequência.

\title{
3 A BOA-FÉ OBJETIVA COMO HARMONIZADORA DO DIÁLOGO DAS FONTES.
}

A necessidade de harmonizar interesses contrapostos para manter o equilíbrio nas relações de comércio eletrônico depende, portanto, do reconhecimento da assimetria dos atores, pois muitos internautas ignoram as formas sutis e sofisticadas de monitoramento empregadas pelas empresas que atuam no setor.

Deve-se levar em conta, também, a dificuldade de o consumidor exercer a sua autodeterminação informacional, ainda que recentemente expressa no Marco Civil da Internet, o que revela a distância entre a previsão normativa e sua efetivação.

Considerando esse quadro e a ausência de legislação específica sobre a proteção de dados pessoais, revela-se a importância de desenvolver o diálogo das fontes, aplicando-se de maneira complementar tanto os princípios da novel legislação, quanto o Código de Defesa do Consumidor. Quanto a esta última legislação, além do princípio da vulnerabilidade, já 
destacado, sobressai a valorização da boa-fé objetiva, compreendida como “[...] regra de conduta fundada na honestidade, na retidão, na lealdade, e, principalmente, na consideração para com os interesses do alter, visto como um membro do conjunto social que é juridicamente tutelado" (MARTINS-COSTA, 1996, p.505).

A boa-fé objetiva, tida como um dos princípios fundantes do direito do consumidor, pode exercer várias funções, tanto hermenêutica, auxiliando na interpretação de cláusulas contratuais, quanto contribuindo para a integração do ordenamento jurídico, já que independentemente da existência de dispositivo legal expresso este princípio cria e impõem deveres de conduta aos negociantes. Ademais, também pode exercer função bloqueadora, pois em nome da boa-fé objetiva os contratantes devem se abster de praticar condutas que lesem os interesses da outra parte. Sua importância como fonte criadora de deveres é destacada por Monsalve Caballero (2008, p.36):

\begin{abstract}
Buena fe es tenida en cuenta como una fuente de creación de especiales deberes de conducta exigibles en cada caso, de acuerdo con la naturaleza de la relación jurídica y con la finalidad perseguida por las partes a través de ella. Las partes no se deben solo a aquello que ellas mismas han estipulado o escuetamente aquello que determina el texto legal, sino a todo aquello que en cada situación impone. Aquí la buena fe debe ser entendida como rectitud y honradez en el trato. Supone un certero comportamiento o una manera de proceder a la cual las partes deben atenerse en el desenvolvimiento de las relaciones jurídicas y en la celebración, interpretación y ejecución de los negocios jurídicos.
\end{abstract}

Sob a influência desse princípio os fornecedores deveriam se comportar com retidão e honestidade durante todas as suas fases da relação negocial, na perspectiva da obrigação como um processo, como ensinado por Clóvis do Couto e Silva (1976). Assim, o agir probo e reto deve pautar o seu comportamento desde o simples contato social ${ }^{6}$, passando pelas etapas de formação do contrato, sua execução, alcançando inclusive o momento pós-contratual, providenciando a guarda segura dos dados pessoais do consumidor, colocando-os a salvo tanto da ação maliciosa dos grupos criminosos, especializados em furtar senhas de cartão de crédito, bem como se abstendo de praticar qualquer transação ou repasse dos dados pessoais do cliente a terceiros.

Em todas essas etapas é imperativo respeitar os deveres especiais de conduta, tais como

\footnotetext{
${ }^{6}$ Couto e Silva (1976, p.89) denomina de contato social a categoria da doutrina do processo social que desempenharia importante papel jurídico. Conforme o autor "Juridicamente, o conceito é explicado por outras razões que não militam no plano sociológico, pois aparece para justificar o nascimento de direitos e obrigações, quando não existe contrato."
} 
[...] a) deveres de cuidado, previdência e segurança; b) deveres de aviso e esclarecimento; c) deveres de informação; d) o dever de prestar contas; e) deveres de colaboração e cooperação; f) deveres de proteção e cuidado com a pessoa e com o patrimônio da contraparte; e g) deveres de omissão e de segredo etc (NOVAIS, 2000, p.29).

Esses deveres decorrentes da boa-fé objetiva, um dos sustentáculos do Código de Defesa do Consumidor, não se dissociam dos preceitos do Marco Civil da Internet, sobretudo em seu artigo $7^{\circ}$, VIII, quando fica evidenciada a necessidade de os contratos conterem cláusulas com informações claras e completas sobre a coleta, uso, armazenamento e tratamento dos dados pessoais, em clara alusão ao princípio da informação e da transparência. No mesmo sentido seguem os demais incisos, com destaque para a proibição do desvio de finalidade e dos excessos, pois somente devem ser captados dados com a devida justificativa, o que só pode ser feito após o devido esclarecimento do consumidor no contrato de prestação de serviços ou termo de uso, onde o internauta deve dar sua aquiescência.

Como se verifica pelo exame dos dispositivos legais, ainda que não esteja declarado textualmente na Lei $\mathrm{n}^{\circ} 12.965 / 2014$, a boa-fé objetiva também foi contemplada, o que permite sustentar que este princípio pode atuar como o liame a partir do qual as duas legislações podem convergir.

Assim, em vez de pensar cada microssistema como autônomo e excludente, a boa-fé objetiva, comum a ambos, atuará como harmonizadora, possibilitando a aplicação simultânea e coerente dessas legislações, o que resultará em proteção mais eficiente para o consumidor/contratante. $\mathrm{O}$ campo de aplicação convergente permite e estimula a aplicação da Teoria do Diálogo das Fontes, construção de origem alemã e propagada no Brasil por Cláudia Lima Marques (2004). Esta autora, ao explicar a teoria, sustenta que

\footnotetext{
Há mais convivência de leis com campos de aplicação diferentes, do que exclusão e clareza. Seus campos de aplicação, por vezes, são convergentes e, em geral diferentes, mas convivem e coexistem em um mesmo sistema jurídico que deve ser ressistematizado. O desafio é este, aplicar as fontes em diálogo de forma justa, em um sistema de direito privado plural, fluido, mutável e complexo (MARQUES, 2004, p.29).
}

A promoção desse diálogo, ademais, vem sendo estimulada pelas próprias legislações elaboradas a partir da segunda metade do século XX, que reconhecem sua insuficiência para responder as demandas atuais. Tanto é assim que o próprio CDC, em seu artigo $7^{\circ}$, dispõe que os direitos ali contemplados não excluem outros previstos em outras leis ou tratados internacionais, da mesma forma que o faz o artigo $3^{\circ}$, parágrafo único, do Marco Civil da Internet. Portanto, a abertura conferida por esses diplomas legais permitem sua 
aplicação simultânea com outras leis (gerais ou especiais) que visem ampliar os direitos originariamente previstos.

A aplicação dessa teoria pode resultar em a) diálogo sistemático de coerência, que ocorre especialmente entre lei geral e lei especial que serão aplicadas simultaneamente, sendo que uma lei serve de base conceitual para a outra; b) diálogo sistemático de complementaridade e subsidiariedade, mais utilizado em casos de antinomias aparentes ou reais, em que será feita a aplicação coordenada das duas leis, sendo que uma complementará a aplicação da outra; c) dialogo das influências recíprocas sistemáticas, o que poderá gerar uma possível redefinição do campo de aplicação de uma lei (ROCHA, 2013)

Esta teoria também permite o diálogo entre duas leis especiais, mas que podem ser complementares, como defendem Benjamin, Bessa e Marques (2009, p.89) quando sustentam que "Em resumo, também entre leis especiais há diálogo das fontes: diálogo sistemático de coerência, diálogo sistemático de complementaridade ou subsidiariedade e diálogo de adaptação ou coordenação". Logo, plenamente possível o diálogo entre Código de Defesa do Consumidor e o Marco Civil da Internet, o que amplia a proteção dos contratantes/consumidores que realizam contratos interativos na internet, especialmente no que concerne à proteção de seus dados pessoais.

\section{CONSIDERAÇÕES FINAIS}

Não se pode ignorar a nova dinâmica que as relações políticas, sociais e econômicas assumiram em decorrência da utilização das tecnologias da informação e da comunicação. Não só ocorreu a desmaterialização de muitas relações jurídicas, com destaque neste artigo para as relações que derivam dos contratos eletrônicos interativos, como houve significativa aceleração na dialética contratual, imprimindo um novo ritmo aos negócios jurídicos.

Seguindo a rapidez dos fluxos, o internauta pode visitar um site de vendas e com poucos cliques eleger o produto ou serviço que deseja, escolha que é seguida da informação de inúmeros dados pessoais que permitirão o pagamento e entrega do produto (em caso de bens corpóreos). Além dos dados que voluntariamente informa, a utilização das TICs por parte das empresas que atuam no segmento ainda permite o constante monitoramento das interações do internauta na web, prática realizada com o objetivo de "conhecer" os potenciais clientes com o objetivo de "oferecer-lhes uma melhor experiência de consumo". Quer seja por meio de atuação declarada ou por meio de estratégias veladas (e ignoradas pelo consumidor), 
a verdade é que o fornecedor recolhe e trata uma série de dados pessoais dos internautas, atividade sobre a qual o titular dos direitos não tem controle.

Tal situação coloca em destaque a importância do tema, especialmente considerando que mesmo em tempos de crise o comércio eletrônico continuou em ascensão, o que aponta para a manutenção (senão ampliação) da vulnerabilidade do consumidor, pois tempos difíceis exigem que as empresas adotem métodos ainda mais agressivos para seduzir o consumidor, o que exige ampliar o monitoramento para manter os mesmos índices de vendas.

A informação sobre os hábitos de consumo e os dados pessoais dos clientes assume uma posição proeminente nesse contexto, constituindo-se em poderoso insumo para as empresas, que não só recolhem e utilizam para potencializar as vendas, como também transferem a terceiros. Esse quadro aponta para a necessidade de pensar em estratégias para tutelar a privacidade do contratante que realiza contratos interativos, especialmente em face da ausência de legislação específica para tutelar os dados pessoais.

É nesse desiderato que se sustentou, no presente trabalho, a possibilidade de realizar o diálogo das fontes, aplicando de maneira simultânea e complementar o Código de Defesa do Consumidor e o Marco Civil da Internet. Tal procedimento é possível graças à tecitura aberta dessas legislações, que expressamente (no artigo $7^{\circ}$ do CDC e no $3^{\circ}$, do Marco Civil da Internet) reconhecem que os direitos ali previstos não excluem outros derivados de leis ou tratados internacionais.

Essa aplicação simultânea pode ser favorecida pelo princípio da boa-fé objetiva, comum a ambas as legislações. Tal princípio, ainda que não declarado expressamente no Marco Civil da Internet, pode ser extraído pela hermenêutica de seu texto, especialmente quando esta lei impõe a observância dos deveres de informação e transparência que devem nortear a conduta de quem recolhe, trata e transmite dados pessoais.

Entende-se que a aplicação conjunta dos dois diplomas legais tem potencial para ampliar a tutela de quem realiza contratos interativos, pois o dever ético derivado da boa-fé objetiva obrigaria o fornecedor a indicar ao internauta se aquele site em que está contratando se utiliza de cookies para rastrear a sua navegação (tanto a atual, quanto futuras visitas). De igual forma, este mesmo princípio determinaria padrões éticos de cuidado e zelo quanto aos dados pessoais recolhidos, o que envolveria todas as fases do contrato, desde o contato social até a pós-contratação.

Por derradeiro, acredita-se que o diálogo dessas legislações especiais, conduzido pelo princípio da boa-fé objetiva, pode servir para suprir eventuais lacunas legais e contratuais, pois sua abertura permite que dele se extraiam outros tantos deveres de conduta que 
eventualmente não estejam contemplados na lei ou nas cláusulas contratuais, o que permitiria dar respostas adequadas aos problemas derivados da dinâmica contratação eletrônica.

\section{REFERÊNCIAS}

BORGESIUS, Frederik Zuiderveen. Segmentação comportamental: Do Not Track e o desenvolvimento jurídico europeu e holandês. Disponível em:

<http://www.politics.org.br/sites/default/files/poliTICs14_frederik_borgesius.pdf >. Acesso em: 24 fev. 2014.

BRASIL. Código de Defesa do Consumidor. Lei No 8.078, de 11 de Setembro de 1990.

Dispõe sobre a proteção do consumidor e dá outras providências. Disponível em:

<http://www.planalto.gov.br/ccivil_03/leis/18078.htm>. Acesso em: 04 jun. 2015.

CASTELLS, Manuel. O poder da Comunicação. Lisboa: Fundação Caloust Gulbenkian, 2013.

Fim de milênio: a era da informação: economia, sociedade e cultura. Traduzido por Klauss Brandini Gerhardt e Roneide Venancio Majer. São Paulo: Paz e Terra, 1999. v. 3.

COMITÊ GESTOR DA INTERNET NO BRASIL. O CGI.br e o Marco Civil da Internet.

Defesa da privacidade de todos que utilizam a Internet; Neutralidade de rede;

Inimputabilidade da rede 2013. Disponível em:

<http://www.cgi.br/media/docs/publicacoes/4/CGI-e-o-Marco-Civil.pdf>. Acesso em: 13 set. 2014.

DONEDA, Danilo. Da privacidade à proteção de dados pessoais. São Paulo, Renovar, 2006.

Princípios de proteção de dados pessoais. In: DE LUCCA, Newton; SIMÃO FILHO, Adalberto; LIMA, Cíntia Rosa Pereira. Direito e Internet III: Marco Civil da Internet III tomo II. São Paulo: Quartier Latin, 2015, p. 369-384.

FEITOSA, Douglas de Lima; GARCIA, Leandro Sumida. Sistemas de Reputação: Um Estudo sobre Confiança e Reputação no Comércio Eletrônico Brasileiro. Rev. adm. contemp.

Curitiba, v. 20, n. 1, p. 84-105, fev. 2016. Disponível em:

$<$ http://www.scielo.br/scielo.php?script=sci_arttext\&pid=S1415-

65552016000100006\&lng=pt\&nrm=iso>. Acesso em: 27 mar. 2016.

GONÇALVES, Maria Eduarda. Direito da informação: novos direitos e formas de regulação na sociedade da informação. Coimbra: Almedina, 2003.

KLEE, Antonia Espíndola Longoni; MARTINS, Guilherme Magalhães. A privacidade, a proteção de dados e dos registros pessoais e a liberdade de expressão: algunas reflexões sobre o Marco Civil da Internet no Brasil (lei no 12.965/2014). In: DE LUCCA, Newton; SIMÃO FILHO, Adalberto; LIMA, Cíntia Rosa Pereira. Direito e Internet III: Marco Civil da Internet III - tomo II. São Paulo: Quartier Latin, 2015, p. 291-367. 
LIMA, Cíntia Rosa Pereira; BIONI, Bruno Ricardo. A proteção dos dados pessoais na fase de coleta: apoontamentos sobre a adjetivação do consentimento implementado pelo artigo 7, incisos VIII e IX do Marco Civil da Internet a partir da Human Computer Interaction e da Privacy by default. In: DE LUCCA, Newton; SIMÃO FILHO, Adalberto; LIMA, Cíntia Rosa Pereira. Direito e Internet III: Marco Civil da Internet III - tomo II. São Paulo: Quartier Latin, 2015, p. 263-290.

MARCO CIVIL DA INTERNET. Seus direitos e deveres em discussão. Disponível em: <http://culturadigital.br/marcocivil/>. Acesso em: 15 jul. 2014.

MARQUES, Cláudia Lima. Confiança no comércio eletrônico e a proteção do consumidor: um estudo dos negócios jurídicos de consumo no comércio eletrônico. São Paulo: Revista dos Tribunais, 2004.

Superação das antinomias pelo Diálogo das Fontes: O modelo brasileiro de coexistência entre o Código de Defesa do Consumidor e o Código Civil de 2002. Revista da Escola Superior da Magistratura de Sergipe (ESMESE), n. 7, 2004.

; BENJAMIN, Antônio Herman V.; MIRAGEM, Bruno. Comentários ao Código de Defesa do Consumidor. Editora Revista dos Tribunais. São Paulo, 2010.

MARQUES, Garcia; MARTINS, Lourenço. Direito da Informática. 2 Ed. Coimbra: Almedina, 2006.

MASINA, Renato Hugo. Análise da aceitação do recebimento de anúncios personalizados, através de smartphones, enquanto o usuário estiver dentro do shopping. Trabalho de conclusão de curso de graduação do curso de Administração da Universidade Federal do Rio Grande do Sul. Disponível em<http://www.lume.ufrgs.br/bitstream/handle/10183/87825/000911628.pdf?sequence=1> Acesso em: 24 fev. 2014.

MENDES, Gilmar Ferreira; COELHO, Inocêncio Mártires; BRANCO, Paulo Gustavo Gonet. Curso de Direito Constitucional. $1^{\text {a }}$ ed., São Paulo: Saraiva, 2007

MONSALVE CABALLERO, Vladimir. LA BUENA FE COMO FUNDAMENTO DE LOS DEBERES PRECONTRACTUALES DE CONDUCTA: UNA DOCTRINA EUROPEA EN CONSTRUCCIÓN. Rev. Derecho. Barranquilla, n. 30, Dec. 2008. Disponível em:

$<$ http://www.scielo.org.co/scielo.php?script=sci_arttext\&pid=S012186972008000200003\&lng=en\&nrm=iso>. Acesso em: 27 mar. 2016.

PÉREZ LUÑO, Antonio-Enrique. Derechos humanos, estado de Derecho y Constitución. 9. ed. Madri: Editorial Tecnos, 2005.

RELATÓRIO WEBSHOPPERS 2014. Disponível em: <img.ebit.com.br/ webshoppers/pdf/WebShoppers2014_2oSeme.pdf>. Acesso em: 21 out. 2014.

. Disponível em: <http://img.ebit.com.br/webshoppers/pdf/33_webshoppers.pdf>.

Acesso em: 26 mar. 2016. 
ROCHA, Igara. A incidência da teoria do diálogo das fontes na defesa do consumidor.

Revista Eletrônica Jurídico-Institucional do Ministério Público do Estado do Rio

Grande do Norte. Natal, RN, ano 3, n. 2, jul./dez. 2013. Disponível em:

<http://www.mprn.mp.br/revistaeletronicamprn/abrir_artigo.asp?cod=1044>. Acesso em: 27

mar. 2016.

SEGURADO, Rosemary; LIMA, Carolina Silva Mandú de; AMENI, Cauê S..

Regulamentação da internet: perspectiva comparada entre Brasil, Chile, Espanha, EUA e

França. Hist. cienc. saude-Manguinhos, Rio de Janeiro, v. 22, supl. p. 1551-1571, dez. 2015.

Disponível em <http://www.scielo.br/scielo.php?script=sci_arttext\&pid=S0104-

59702015001001551\&lng=pt\&nrm=iso>. Acesso em: 27 mar. 2016. 